\title{
LAS CIUDADES ESCRIBEN SU AUTOBIOGRAFÍA. ESPACIO URBANO Y ESCRITURA AUTOBIOGRÁFICA
}

\author{
Fernando ROMERA GALÁN \\ UNED-SELITENAT
}

\section{RESUMEN}

El presente artículo es un acercamiento a la condición del signo espacial en la literatura autobiográfica. Se pretende comprobar hasta qué punto el espacio urbano en esta tipología textual se acerca a la ficción a partir de procedimientos no autobiográficos como el recurso al olvido. Y sobre todo, tratar de explicar cómo son las grandes ciudades las que procuran el despertar de la autobiografía contemporánea a partir de una especial manera de entender la intimidad y la anonimia.

Palabras clave: autobiografía, ciudad, memoria.

\section{ABSTRACT}

This research article is an approach to the condition of the sign of space in autobiographical literature. It intends to prove how urban space approaches to fiction from non-autobiographical procedures as the use of oblivion. And above all, try to explain how big cities usually provides the awakening of contemporary autobiography from a special understanding of privacy and anonymity.

Key words: autobiography, city, memory.

\section{LA «CONDICIÓN VEGETAL» DEL HOMBRE: LA CIUDAD COMO CURRÍCULUM}

La ciudad ha sido un signo literario muy estudiado en sus relaciones con ciertos géneros literarios. En lo que respecta a la autobiografía, se ha pasado siempre muy de puntillas, considerando que el espacio urbano era sólo la 
situación espacial del autor en el tiempo del hecho narrado. Pero también es cierto que hay ciertas características comunes en el tratamiento del espacio en general y de la ciudad en particular en los escritos autobiográficos y que hay ciertos procesos de ficcionalización en la autobiografía que parten del tratamiento que se le da al signo espacial.

Por comenzar por algún ejemplo, diremos que, en muchas ocasiones, la narración autobiográfica recoge las necesidades, las esperanzas o los deseos en forma de búsqueda de un espacio. Así, los viajes a lugares idealizados son habituales en este tipo de textos. Suele coincidir con memorias de juventud que responden a la necesidad de exploración personal, asociados a lecturas o a viajes literarios. Este sería el caso de Santiago Ramón y Cajal tras terminar sus estudios de Medicina y embarcarse hacia Cuba:

También yo estoy asqueado de la monotonía y acompasamiento de la vida vulgar. Me devora la sed insaciable de libertad y de emociones novísimas. Mi ideal es América, y singularmente la América tropical, jesa tierra de maravillas, tan celebrada por novelistas y poetas!... Sólo allí alcanza la vida su plena expansión y florecimiento (Ramón y Cajal, 1981: 203).

Estos cambios espaciales suelen coincidir con etapas cambiantes de la vida. A menudo es el lugar el que parece transformar al personaje que tiende a buscar una explicación en el lugar al que accede. Así, las descripciones suelen abundar en mayor medida, de manera que el lugar y el viaje a ese lugar tienen, a menudo, algo de ascético y de integrador en la vida adulta.

Nos encontraríamos aquí con la espinosa cuestión sobre la adscripción de la literatura de viajes en el género común de la autobiografía, estudio que desbordaría el interés de este trabajo y del que daremos sólo unas breves pinceladas. En principio, la aparición del espacio urbano dentro de los denominados libros de viajes, o crónicas de viajes, implica una visión subalterna del signo espacial urbano, puesto que se plantea, no ya como un lugar propio, sino como una entidad comparativa. El viaje pone en contraste los espacios. Fernando Durán establece una premisa que nos parece interesante; a saber: cómo una autobiografía toma la forma de un libro de viajes y hasta qué punto esos mismos viajes no son sino un aspecto de la formación personal, de la configuración del yo que se nos va presentando en el texto:

Lo que me interesa destacar en estas páginas no es el tipo de libro de viajes que efectúa este autobiógrafo, sino el proceso mediante el cual un libro de viajes se convierte en un elemento definidor de una identidad individual: es decir, qué concepción del yo se deriva de una autobiografía que deviene libro de viajes (Durán, 1991: 75-88). 
Son muchas las autobiografías que presentan forma de crónica de viajes. En principio, porque gran parte de los escritores de memorias han sido grandes viajeros, en parte porque la propia crónica de viajes encierra la necesidad de hablar de uno mismo y de las vivencias propias. Sería muy difícil prescindir de la identificación personal en todos los viajeros del XIX por España. Una buena parte de sus crónicas se dedica a tratar impresiones personales y vivencias en los lugares recorridos.

Por otro lado, el viajero se traslada por múltiples motivos. En la literatura del XVIII por olvidar la monotonía y pobreza provinciana española. Así lo expone Fernando Durán:

También se ha hecho notar la facilidad con que tanto la autobiografía como el diario derivan en este periodo hacia el género viajero. Y no se trata de una literatura de viajes centrada en lo pintoresco de las costumbres, en el color local o el paisaje: existe una marcadísima hegemonía del espacio urbano y además del espacio urbano desarrollado y civilizado, el que presenta una mayor riqueza intelectual y de trato social, porque estos hombres, al contrario que los románticos, no viajan para obtener emociones fuertes o tomar contacto con pasiones primitivas, sino para formarse y aprender (Durán, 1991: 84).

La vinculación de los textos autobiográficos a los espacios urbanos es, pues, antigua y relevante. Y no únicamente por que los autores viajaran, obviamente, sino porque el espacio urbano se había venido a convertir en una señal distintiva de cultura: son los comienzos del cosmopolitismo.

Este cosmopolitismo tendrá, a partir de ahora, un interés destacado, por cuanto no sólo hay que ser cosmopolita, sino demostrar públicamente ese rasgo personal. Y una de las características es la demostración autobiográfica de los viajes. Entre las muchas razones que los autores dan para escribir una autobiografía está la de mostrarse públicamente, y esa exhibición pública de uno mismo requiere también la propia adjetivación, el propio lucimiento, el «currículum urbanita». Las ciudades visitadas, los viajes realizados son, además, una marca personal, por lo que el autor va a seleccionar cuidadosamente qué lugares pretende enseñar en los textos. No es un problema de veracidad, en este caso, sino de deixis, de autoseñalamiento, de cómo es capaz de mostrarse en público. Porque, evidentemente, en un texto de memorias se selecciona aquello que se cree más relevante y son muchos los lugares visitados que van a obviarse.

Venimos hablando de la importancia que tiene el viaje y la educación personal en la literatura del siglo XVIII. Pero no sólo es importante este aspecto en la literatura neoclásica, sino que llega hasta bien entrado el siglo XX. Muchas autobiografías, literarias o no, tratan el aspecto de la evolución cultural y educativa personal. Así, autores que han hecho de la cultura el vehículo o hilo 
conductor de una vida, redundan en este aspecto y, significativamente, también hacen hincapié en todos los viajes y desplazamientos que se han dado en su vida. Hemos propuesto anteriormente el ejemplo de Ramón y Cajal, quien, en la práctica totalidad de los capítulos que ocupan su autobiografía, refleja, junto con otros aspectos de su vida, el viaje en el que se encierra esa etapa o momento de su vida. (Ramón y Cajal, 1981: 26-153). Así: Mi estancia en Valpalmas; Mi traslación a Jaca; Dispone mi padre llevarme a Huesca para continuar mis estudios; el Ebro y sus alamedas; Me embarco en Cádiz con rumbo a la Habana.

Estos viajes de erudición o de formación son comunes. Galdós también señala en sus memorias su orgullo por ser el único español que parece haber visitado la tumba de Shakespeare. Esta suerte de narcisismo viajero es más habitual de lo que parece y, en cuanto al género autobiográfico, mantiene la necesidad del autor por elevarse literariamente:

En los voluminosos libros donde firman los visitantes he visto que la mayor parte de los nombres son ingleses y norteamericanos; contadísimos los de franceses e italianos, y españoles no vi ninguno. Creo que soy de los pocos, si no el único español, que ha visitado aquella Jerusalén literaria y no ocultaré que me siento orgulloso de haber rendido este homenaje al altísimo poeta cuyas creaciones pertenecen al mundo entero y al patrimonio artístico de la humanidad (Pérez Galdós, 1975: 153).

Por lo tanto, podemos evidenciar que el autor de autobiografías tiende, en muchas ocasiones a uno u otro espacio vital. Bien sea la ciudad, bien el campo, los pueblos pequeños, las grandes urbes... el lugar se presenta, muchas veces en los textos autobiográficos como una tendencia personal que refleja las necesidades y los gustos personales del autor. Es decir, existe una identificación íntima entre espacio y protagonista, una vinculación metonímica.

Los viajes a las grandes ciudades suelen provocar, además, modificaciones en los gustos y aficiones literarias. Es decir, el conocimiento de la ciudad nueva, generalmente una gran ciudad cultural, parece ser percibido como un cambio profundo en el conocimiento de la literatura que parece verse influenciada por el aire del cosmopolitismo. A Galdós le ocurre en su infancia:

Con las personas que me llevaron a París volví a Madrid sin incidente notable, y en el intervalo entre este primer viaje y el segundo (1868) saqué del cajón donde yacían mis comedias y dramas y los encontré hechos polvo; quiero decir, que me parecieron ridículos y dignos de perecer en el fuego (Pérez Galdós, 1975: 197).

La visión del espacio personal suele apreciarse como una tendencia necesaria desde el discurso autobiográfico de la vejez. La imagen personal de una vida cumplida tiende a contemplar el espacio como una tendencia necesaria. 
Proponemos el ejemplo de Miguel Delibes, quien ve intensificada su relación con su ciudad natal con Valladolid cuando llega al final de su carrera literaria:

He aquí un hecho cierto: cuando yo tomé la decisión de escribir, la literatura y el sentimiento de mi tierra se imbricaron. Valladolid y Castilla serían el fondo y el motivo de mis libros en el futuro. Pero semejante decisión no implica que Valladolid y Castilla me deban algo, sino, al contrario soy yo el que me siento deudor, porque de ellos he tomado no sólo los personajes, escenarios y argumentos de mis novelas, sino también las palabras con que han sido escritas (Delibes, 1996: 199).

Podemos extraer varias consecuencias de estos textos de Delibes. En primer lugar que el espacio sufre un proceso de personalización (no de personificación, o al menos, no únicamente). La ciudad es el espacio y las gentes con todo lo que ello conlleva: lugares, personas, lengua, usos de habla... Los recuerdos se convierten en la imaginería de la escritura, pero también la vinculación a través del habla particular de esa ciudad. Delibes recuerda, pero también hace presente el espacio a través de la forma del castellano de Valladolid. Las imágenes son de escenarios, descripciones espaciales, pero el germen de la literatura también es el recuerdo de cómo se hablaba sobre esos lugares:

En Valladolid aprendí a hablar, en aquel Valladolid del tren burra y los amarillos tranvías con jardinera, de los pregones en las viejas rúas y los charlatanes en la Plaza Mayor, de la hermana Remedios en las Carmelitas del Campo Grande, y el hermano Enrique en el colegio de Lourdes... Aquellas voces que arrullaron mi infancia fueron el germen de mi expresión futura (Delibes, 1996: 199).

Es lo que Delibes reconoce con el título de «condición vegetal» y que hemos reproducido como título de este epígrafe. Condición que viene dada por una especie de sentimiento de arraigo contraída por el nacimiento y el paso de los años y que se convierte en un vínculo de vida. Lingüísticamente da lugar a algunos rasgos de escritura que particularizan la expresión, literaria o no. No es sólo la posibilidad de una expresión dialectal o una modalidad de habla; es que el propio espacio se convierte en esa colección de imágenes que va a ser precisa para abordar la creación literaria; es decir, tarde o temprano esa espacialización va a ir apareciendo en los textos que el autor produzca. Lo explica de la siguiente manera:

A mí me nacieron aquí, en la vallisoletana Acera de Recoletos, y aquí arrai-
gué en poco tiempo tan profundamente que ya de niño, trasladarme a otro
lugar hubiera comportado un desgarramiento, el dolor y los riesgos que lleva
consigo todo trasplante. Sencillamente estoy aquí, sigo aquí, porque no me
hubiera acertado a estar en otra parte, porque sin este cepellón de tierra bajo
mis pies, me hubieran faltado nutrientes y tal vez mi imaginación se hubiera
esterilizado (Delibes, 1996: 200).

Anales, 24, 2012, pp. 307-318 
El pensamiento de Delibes sobre estas condiciones espaciales de la vida es profundamente orteguiano y viene a explicar cómo una de las circunstancias que más le han influido ha sido precisamente la vivencia del espacio urbano: «la circunstancia de que habló Ortega era para mí Valladolid» (Delibes, 1996: 201).

Y, como venimos explicando, esta relación personal con la ciudad se produce a través de los otros: la familia, los amigos, las instituciones... Esa individuación espacial es la que da lugar a la expresión «mi ciudad» que encierra no sólo una connotación puramente posesiva o de relación causal, sino una relación afectiva. En el caso de las referencias a la ciudad propia el adjetivo posesivo suele tener, a menudo, ese matiz semántico afectivo:

Ahora se dice de estos sentimientos que son viscerales. Yo ceñiría un poco más este adjetivo: diría que son cordiales. Porque a esas alturas de la vida a las raíces iniciales que me ataban a mi ciudad, había que ir añadiendo otras nuevas de las que nunca podría ya desasirme: mis queridos muertos, mi familia, mis amigos, mi Norte de Castilla, mi Escuela de comercio, mis calles de todos los días, mis campesinos, mi tierra...Podrían existir otros amigos, acaso otros periódicos, otras Universidades, otros campesinos, otras tierras sin duda, pero nunca serían lo mismo (Delibes, 1996: 201).

Algunas de estas obras citadas en este epígrafe, según Romera Castillo, quien ha estudiado algunos aspectos de la escritura del autor vallisoletano, pueden ser consideradas como abiertamente autobiográficas, caso de Mi vida al aire libre (1989) y Pegar la hebra (1990). Según el profesor:

Hay otras obras que no se insertan en el mundo novelístico, sino que han surgido de experiencias directas con la realidad y que constituyen una especie de «crónicas de viajes» (Romera, 2006: 280).

Aún y con todo, creemos, en la obra de Delibes siempre se puede apreciar esa relación especial con el entorno vital que produce la esencial «condición vegetal» del hombre. Independientemente del grado de autobiografismo que encontremos en una obra, siempre vamos a hallar una sustancial identificación espacial con el «yo»y, consecuentemente, con el hecho narrativo.

Podemos esbozar, por lo tanto, que ese sentimiento de arraigo es una de las bases para la aparición de ciertas formas de expresión escrita autobiográfica. Los casos que hemos visto aportan una visión de cómo el lugar de nacimiento o de desarrollo se incorporan a la propia vida de manera que la formulación de este espacio en la escritura se hace imprescindible y se connota de manera notable. 


\section{LA DESMEMORIA FICCIONALIZA LOS LUGARES}

Siguiendo con lo dicho anteriormente, ciudad y protagonista, a menudo, se sienten identificados. Una de las apariciones habituales de la ciudad en los textos autobiográficos es la del espacio personificado. La ciudad representa, no a sí misma, sino a sus habitantes o sus gentes. A menudo, incluso el autor puede referirse a ella de manera personal, reflejada en una suerte de personaje que vive en las páginas del texto. Esto es lo que hace Galdós en sus memorias:

¿Qué tendrá Madrid, que está tan cabizbajo y cariacontecido? Parece que una gran desgracia le amarga, o que una nube siniestra, preñada de tempestades, amenaza con descargar sobre su cabeza todo un arsenal de rayos, centellas y demás proyectiles atmosféricos? (Galdós, 1975: 35).

Esta manera de reflejar la identidad de la ciudad se da en mayor medida cuanto mayor es la relación personal y de conocimiento que el autor posee. El caso de Galdós es significativo porque su vida en Madrid fue, también, generadora de espacios novelísticos. Esta relación personal con la ciudad es tan profunda que no duda en referirse a ella de la siguiente manera: «Todas las funciones orgánicas de ese señor grave y juicioso que se llama Madrid están alteradas» (Galdós, 1975: 36).

Este extremo de identificación metonímica es común entre la autobiografía y la novela. Incluso algunas formas de personificación. Pero también el proceso contrario, el de reificación. Dionisio Ridruejo, en sus memorias, explica esto mismo refiriéndose a Madrid:

Bueno; aquello era un Madrid escenario, o más bien un Madrid cosa y no propiamente un Madrid pueblo, si se salvan las tres o cuatro referencias sociales a las que acabo de aludir (Ridruejo, 2007: 111).

Sin embargo, la cuestión de la relación entre el personaje y el espacio urbano no es baladí. Normalmente, los diferentes géneros implican diferencias de expresión narrativa. En el caso de las memorias, la ciudad tiende a aparecer desdibujada en muchas ocasiones y perfectamente descrita en otras. La cuestión de la memoria hace que no exista mucha diferencia entre el signo en la novela y estas memorias. La expresión de esta duda es, a menudo, literal. Volviendo al autor, la recreación de algunos espacios urbanos se ve teñida de una ficción involuntaria:

Nos alojamos en un hotelito de categoría media que estaba y seguramente sigue, en la plaza Mayor: El hotel Victoria. Recuerdo un comedor abovedado, con pinturas. El balcón de nuestro cuarto daba a la calle enfrente de la iglesia de San Miguel. ¿Es verdad que vi el incendio que se comió la cubierta de esa 
iglesia y consumió buena parte de su tesoro interior? [...] Si no es real este recuerdo, será que se han superpuesto las imágenes (Ridruejo, 2007: 99).

Pero, lo que es más. Incluso en los casos en que esto es fácilmente verificable, el propio autor reniega de esta posibilidad para dejar la ficción fluir en el texto:

Para ponerlo en claro me bastaría leer la crónica local. No merece la pena. En mi memoria están los tizones volantes, el toque de las campanas a rebato y el crecimiento de las llamas (Ridruejo, 2007: 99-100).

Por lo tanto, la relación memorística de los hechos narrados no supone su certeza; es más, incluso esta certeza es, a menudo, rechazada por motivos más o menos sentimentales. Por todo ello, el espacio urbano, y el espacio en general, guarda, también, un valor de signo muy similar al de la novela y otros géneros de ficción.

\section{LA GRAN CIUDAD ESCRIBE SU AUTOBIOGRAFÍA ÍNTIMA}

Es habitual, y depende de innumerables factores que van desde la perspectiva personal a las modas estéticas literarias, la aparición de la dicotomía o dialéctica entre la preferencia entre el campo y la ciudad. Diríamos que es casi generalizado. Si seguimos con Ridruejo, la permanente referencia a Madrid y la capitulación de las memorias en puros viajes de ciudad en ciudad, se rompe, sin embargo, con su declaración acerca de Ronda «La tierra es inagotable y nada alimenta tanto la imaginación como verla cambiar con las estaciones. (Por eso en las ciudades me seco)» (2007: 407).

Esto es lo que dice Ridruejo, pero los casos son innumerables. Baroja no entiende, por poner el caso contrario, la obsesión literaria por el campo. En la tradición autobiográfica, podemos encontrar la dualidad campo-ciudad en muchas ocasiones. Los diarios de Andrés Trapiello son también un buen ejemplo de cómo se trata de oponer el campo representado por sus estancias en Extremadura, pintado como una suerte de paraíso rural, frente a la ciudad de Madrid que no está, sin embargo, teñida de matices o connotaciones negativas. La figura del flâneur u observador íntimo de los espacios urbanos tiene mucho que ver con esta dualidad en la que no hemos de considerar al habitante del espacio urbano sólo como un habitante que vive la ciudad plenamente, sino como un escrutador de costumbres y vidas que se mantiene a una prudente distancia de ella. Esta ha sido la reacción de Baroja, como explicábamos anteriormente. Sus salidas son también las de un espectador que trata de contemplar la vida más como un investigador que como un habitante integrado en el entorno. 
Así, reconoce que:

Comienza a haber un deseo relativo de conocer la tierra donde se vive y cierto afán por viajar; no hay ese prestigio único de París, y se siente afición al campo, a las excursiones, a los viajes pequeños y a las ciudades de provincia (Baroja, 1997: 650).

El interés por el campo se podrá reconocer más ampliamente en otros autores de los primeros años del XX, sobre todo en Unamuno o, más aún, Azorín o Machado.

Parece obvio sospechar que esa contraposición comienza en el momento en el que la ciudad empieza a ganar protagonismo en la vida intelectual y afectiva de sus habitantes. Y esto comienza a suceder en el siglo XIX, fundamentalmente, aunque ya apunta esta tendencia en los ilustrados del XVIII. Cuando Julián del Casal escribe la siguiente carta no está dando una opinión personal sobre la vida en el campo, sino una presuposición estética derivada de la influencia que la gran ciudad ha ejercido sobre él y su vida libresca:

Hace unos días que llegué del campo y no había querido escribirle porque traje de allí muy malas impresiones. Se necesita ser muy feliz, tener el espíritu muy lleno de satisfacciones para no sentir el hastío más insoportable a la vista de un cielo siempre azul, encima de un campo siempre verde. La unión eterna de estos dos colores produce la impresión más antiestética que se pueda sentir (Casal, 1963: 82).

Es a partir de los movimientos y las actitudes finiseculares (el propio Julián del Casal, los poetas malditos, la bohemia de las grandes ciudades...) cuando la ciudad comienza a tener espíritu, o, en palabras de Borges, «autobiografía». Y comienza a definirse por oposición al campo, por oposición a las pretendidas esencias estéticas y espirituales que la vida rural venía trayendo desde la tópica y la retórica clásica que se perpetúa en el Beatus Ille horaciano y todo el Siglo de Oro español:

Yo afirmo que solamente los países nuevos tienen pasado, es decir, recuerdo autobiográfico de él; es decir tienen historia viva. Yo no he sentido el liviano tiempo en Granada, a la sombra de torres cientos de veces más antiguas que las higueras y sí en Pampa y Triunvirato, insípido lugar de tejas anglizantes ahora, de hornos humanos de ladrillo hace tres años (Borges, 1974: 107).

Podemos pensar, pues, que fueron los autores del siglo XIX y principios del $\mathrm{XX}$ los que modificaron este sentimiento y lo convirtieron en oposición. No era ya posible considerar una compatibilidad entre campo y ciudad, si no es como una concepción histórica, como un recuerdo de la pasada belleza, como una imagen de la muerte. Y ha de ser por esta razón por la que los autores simbolistas verán integrarse ambas en las pequeñas ciudades frente a las grandes 
capitales, los que entenderán que el viejo concepto de ciudad está muerto, que los conceptos sociales burgueses que habían dado lugar al viejo espacio urbano ya, simplemente, no existían. Si la ciudad se había comportado como una suma de intereses sociales establecidos en clases, donde cada uno tenía su lugar establecido históricamente, la nueva ciudad emerge como una oportunidad estética, como un verdadero «espacio» que puede ser modificado y recreado sobre unos conceptos éticos nuevos. Las «ciudades muertas» se opondrán, definitivamente, a las «ciudades».

A este respecto es muy interesante la obra de Álvaro Salvador, quien recogió el verso de Julián del Casal para dar título al libro: El impuro amor de las ciudades (2007).

En él se hace un recorrido por la aparición del nuevo concepto de ciudad que nace con el modernismo, fundamentalmente con el modernismo hispanoamericano, constatando la importancia del espacio urbano:

El espacio urbano es uno de los ingredientes más novedosos y decisivos que la modernidad introduce en la lógica interna de la literatura y el arte finiseculares (Salvador, 2007: 19).

La disolución de la ciudad antigua tendría como modelo la nueva fisonomía de la ciudad de París, que, al fin y al cabo, termina por ser el referente urbano de todos estos autores modernistas. La ruptura con la vieja ciudad será experimentada en el nuevo urbanismo y abrirá la puerta a un nuevo modo de ver y vivir el espacio en torno: la mirada del denominado flâneur, cuya primera experiencia vendrá de la mano -del ojo- de Baudelaire. Sobre este punto opina lo siguiente:

La revolución experimentada por las ciudades europeas e hispanoamericanas a finales de siglo, según el modelo que proporcionó Haussmann y sus reformas en el centro de París, demoliendo la ciudad medieval y abriendo grandes redes viarias en forma de bulevares, supondrá una nueva geografía para la mirada atenta del artista y un nuevo lugar de relaciones -asimismo nuevas- para su capacidad de percepción e interpretación del mundo exterior (Salvador, 2007: 29).

Y si esta repercusión será grande para la poesía o la novela, igualmente importante, si no más, lo será para la escritura autobiográfica por cuanto estas modalidades reflejarán con especial énfasis la importancia que tiene el nuevo espacio recién nacido para el autor y su obra.

Quien se ocupó también de estos aspectos, desde un punto de vista sociológico fue, a principios del siglo XX, Georg Simmel. En diferentes artículos y libros como El individuo y la libertad o «Metrópolis y mentalidades», Simmel explica el cambio de mentalidad que se produce en la sociedad del siglo XIX 
en torno a las transformaciones urbanas y la oposición a la ciudad. Ve en las grandes ciudades europeas (fundamentalmente en Berlín) la nueva forma de organización que marcaría los procesos sociales durante y tras el fenómeno de la industrialización. Destaca las distinciones entre campo y ciudad como los elementos en torno a los que se habían venido estableciendo las descripciones de los dos modelos de sociedad que se corresponderían con formas contrapuestas de organización. Las grandes ciudades se opondrían a las ciudades más pequeñas, «ciudades muertas» según la nomenclatura que comenzara Rodenbach, que, durante el siglo XIX -y en el siglo XX aún en España- mantendrían aún formas de organización «comunales». Conceptos como anonimato, individualización, libertad, secreto, superficialidad... se le irán añadiendo a las connotaciones urbanas frente a los contrarios de las formas de organización rurales. Y, por lo que interesa a nuestro estudio sobre autobiografía y espacio urbano, es interesante destacar cómo ese concepto de anonimato y secretismo irá organizando el pensamiento de los autores del XIX, de manera que la gran ciudad será percibida, paradójicamente, como el modelo de espacio íntimo. Porque las repercusiones que tiene el anonimato en la gran ciudad son absolutamente diferentes que las relaciones que se producen en la ciudad pequeña:

La actitud de los urbanitas entre sí puede caracterizarse desde una perspectiva formal como de reserva. Si al contacto constantemente externo con innumerables personas debieran responder tantas reacciones internas como en la pequeña ciudad, en las que se conoce a todo el mundo con el que se tropieza y se tiene una relación positiva con cada uno, entonces uno se atomizaría internamente por completo y caería en una constitución anímica completamente inimaginable. En parte esta circunstancia psicológica, en parte el derecho a la desconfianza que tenemos frente a los elementos de la vida de la gran ciudad que nos rozan ligeramente en efímero contacto, nos obligan a esta reserva, a consecuencia de la cual a menudo ni siquiera conocemos de vista a vecinos de años y que tan a menudo nos hace parecer a los ojos de los habitantes de las ciudades pequeñas como fríos y sin sentimientos (Simmel, 1986: 253).

Por lo tanto, no ha de extrañar que la gran ciudad haya generado interés autobiográfico como espacio de lo autónomo y lo personal, cuando, en realidad, es el verdadero lugar de reflexión interior y de espacio de intimidad.

¿Sería pensable una narración auténticamente autobiográfica en el marco de las relaciones sociales de una ciudad pequeña? De hecho $y$, con respecto a este último extremo, podemos acercarnos a un buen número de casos en los que ha dado lugar a novelas en clave o narraciones más o menos crípticas en las que se puede distinguir material autobiográfico tras el disfraz de los 
seudónimos o la modificación de los lugares. Este es el caso, por ejemplo, de la novela de Óscar Esquivias El suelo bendito (2000), en el que se plasma la ciudad de Burgos y algunos de sus personajes bajo apariencias que permiten intuir la vida y pecados de la ciudad y sus ciudadanos, pero impide percibirla como una auténtica narración autobiográfica. Si el autor se siente comprometido en la historia de manera que esa implicación pueda romper el equilibrio social de una sociedad tradicional, la autobiografía se camufla bajo otras apariencias. La gran ciudad, ocultando al autor en la multitud, favorece la materia autobiográfica.

\section{BIBLIOGRAFÍA}

Baroja, Pío, Desde la última vuelta del camino, Barcelona, Círculo de Lectores, 1997.

BORGES, Jorge Luis, Obras completas, Volumen I, Buenos Aires, Emecé Editores, 1974.

CASAL, Julián del, «Carta a Esteban Borrero Echeverría», en: Julián del Casal, Prosas. Tomo III, edición del Centenario, Biblioteca Básica de Autores Cubanos, Consejo Nacional de Cultura, La Habana, 1963.

DelibES, Miguel, He dicho, Barcelona, Destino, 1996.

DURÁN LÓPEZ, Fernando, «Autobiografía, espacio urbano e identidad del intelectual ilustrado: el caso de Mor de Fuentes», Cuadernos de Ilustración y Romanticismo, Revista del grupo de estudios del siglo XVIII, 3, 1991, pp. 81-97.

EsQuivias, Óscar, El suelo bendito, Madrid, Algaida, 2000.

PÉREZ GALDÓs, Benito, Recuerdos y memorias, Madrid, Tebas, 1975.

RAMÓn y Cajal, Santiago, Mi infancia y juventud, Madrid, Espasa Calpe, 1939.

Ridruejo, Dionisio, Casi unas memorias, Barcelona, Península, 2007.

Romera CASTillo, José, De primera mano. Sobre escritura autobiográfica en España. Madrid: Visor Libros, 2006.

SALVADOR, Álvaro, El impuro amor de las ciudades. Madrid: Visor Libros, 2007.

SIMMEL, Georg, El individuo y la libertad. Ensayos de crítica de la cultura, Barcelona, Península, 1986.

SIMMEL, Georg, «Metrópolis y mentalidades», Ábaco 6, Barcelona, 1989, pp. 61-69.

Fecha de recepción: 20-1-2012

Fecha de aceptación: 30-5-2012 